\title{
Evaluation of early subclinical cardiotoxicity of chemotherapy in breast cancer
}

\author{
Hayri Alıcı, Ozan Balakan1, Süleyman Ercan², Musa Çakıcl ${ }^{2}$, Fethi YavuZt, Vedat Davutoğlu² \\ Clinic of Cardiology, 25 Aralık State Hospital, Gaziantep-Turkey \\ ${ }^{1}$ Department of Oncology, Faculty of Medicine, Sütçü İmam University; Kahramanmaraş-Turkey \\ ${ }^{2}$ Department of Cardiology, Faculty of Medicine, Gaziantep University; Gaziantep-Turkey \\ ${ }^{3}$ Department of Cardiology, Faculty of Medicine, Adıyaman University; Adıyaman-Turkey \\ ${ }^{4}$ Clinic of Cardiology, Dr. Ersin Arslan State Hospital; Gaziantep-Turkey
}

ABSTRACT

Objective: Cardiac effects of chemotherapy are usually recognized after clinical symptom or sign occurrence in patients with breast cancer. In this study, we aimed to determine the potential subclinical cardiotoxic effects of chemotherapy that were given lower dosage than well known cardiac safety dosage limits in patients with breast cancer during early period.

Methods: Fifty-one patients consecutively enrolled to this prospective cohort study. All patients were diagnosed as breast cancer at oncology hospital in University of Gaziantep. Before chemotherapy, all of the patients underwent to detailed ECG and echocardiography (ECHO) examinations. After 6 months, detailed ECG and ECHO examinations were repeated and compared with baseline values. Statistical analysis was performed using Shapiro-Wilk tests, Student t-test and Spearman correlation test.

Results: The average age of patients was 51 and one was male. Statistically significant decrease in ejection fraction was found after treatment $(62.3 \% \pm 3.3$ and $59.9 \% \pm 5.9, p=0.002)$. Evaluation of diastolic parameters; significant increase in the transmitral A flow velocity and significant decrease of E/A ratio were observed on Doppler ECHO analysis $(77.4 \pm 19.1 \mathrm{~cm} / \mathrm{sec}$ versus $86 \pm 18 \mathrm{~cm} / \mathrm{sec}, p<0.001 ; 1.01 \pm 0.3$ versus $0.9 \pm 0.2, p=0.03$, respectively). On tissue Doppler analysis we observed that significant reduction in the value of $E^{\prime}$ and significantly increase $E / E^{\prime}$ ratio were present $(12.5 \pm 3.6 \mathrm{~cm} / \mathrm{sec}$ versus $10.7 \pm 2.9 \mathrm{~cm} / \mathrm{sec}, \mathrm{p}=0.001 ; 6.6 \pm 2.9$ versus $7.7 \pm 3.3, p=0.04$, respectively).

Conclusion: Chemotherapy has detrimental subclinical effect on both of systolic and diastolic function in early six months period despite the prescription of lower dosage of chemotherapy than well-known cardiac safety dosage limits. Tissue Doppler imaging may be more sensitive than ECG, conventional ECHO and Doppler for determining the subclinical cardiac damage. (Anatolian J Cardiol 2015; 15: 56-60)

Key words: breast cancer, chemotherapy, echocardiography, tissue Doppler imaging, cardiotoxicity

\section{Introduction}

Breast cancer is the most common type of cancer in women. Many antineoplastic agents used to treat breast cancer have potentially cardiotoxic effects and may lead to chemotherapy induced cardiomyopathy and heart failure (1). There are many ways for cardiac damage caused by chemotherapy such as cardiomyopathy, ischemia, arrhythmia and pericarditis. In addition, some chemotherapeutic agents cause electrocardiographic early repolarization abnormalities and in turn, this may lead to ventricular tachycardia (1). Especially, anthracyclines and trastuzumab are the cornerstones in breast cancer therapies (2). However, cardiotoxic effects highly limit their use $(3,4)$.

Electrocardiography (ECG) and echocardiography (ECHO) are used as non-invasive methods for monitoring cardiac toxicity in cancer patients (5). Arrhythmia and conduction abnormalities could be detected together with non-specific ST-T changes in ECG, distortion in QRS duration and its morphology, changes in OT interval and its dispersion (6). ECHO provides a lot of information about apparent systolic dysfunction, however diastolic dysfunction can also be detected in patients whose ejection fraction is preserved $(5,7)$. In addition, tissue Doppler imaging (TDI) gives more information about cardiotoxicity. Knowledge about TDI and compare with conventional ECHO in early period after chemotherapy is lacking. In this study, we aimed to determine the potential subclinical cardiotoxic effects of chemotherapy that is used under recommended dosage limits and to compare tissue Doppler imaging with conventional ECHO between chemotherapy agents in patients with breast cancer during early period.

Address for Correspondence: Dr. Hayri Alıcı, 25 Aralık Devlet Hastanesi; Gaziantep-Türkiye

Phone: +90 5326229242 Fax: +90 3423388618 E-mail: mhayrialici@hotmail.com

Accepted Date: 03.12.2013 Available Online Date: 02.04.2014

(C) Copyright 2015 by Turkish Society of Cardiology - Available online at www.anakarder.com DOI:10.5152/akd.2014.5185 


\section{Methods}

\section{Study design}

This study was a prospective cohort study.

\section{Study population}

Fifty-one consecutive patients who were scheduled chemotherapy for breast cancer were enrolled to the study between January and December 2011. Patients received chemotherapy agents and/or radiotherapy by clinical decision of oncologist. Chemotherapy was applied recommended dosage accepted cardiac safety dosage limits. Patients were grouped according to chemotherapy agents such as doxorubicin, epirubicin and trastuzumab. In addition, subgroups were created by combination therapy of anthracycline double (with cyclophosphamide) or triple (with cyclophosphamide +5 -fluorouracil). The exclusion criteria of study; known coronary artery disease or heart failure $(\mathrm{EF}<50 \%)$ and previously chemotherapy and/or radiotherapy exposure. The study protocol was reviewed and accepted by Ethical Review Board. The informed consent was obtained in all patients.

\section{Study protocol}

Patients' demographic data were recorded. The stage of the cancer, the presence of estrogen or progesterone receptor and HER2 receptor were evaluated. At the beginning examinations, patient were examined for cardiac diseases and cardiovascular risk factors such as diabetes, hypertension and dyslipidemia. Baseline electrocardiogram and echocardiographic examinations were performed to all patients before chemotherapy. Number of chemotherapy cures and cumulative chemotherapy dosage were noted. At the sixth month of treatment, detailed ECG and ECHO examinations were repeated and compared with baseline values.

\section{Baseline clinical examinations}

All patients underwent clinical examination with special emphasis on blood pressure, pulse, height and weight with the body mass index (BMI) calculated $\left(\mathrm{kg} / \mathrm{m}^{2}\right)$ and then underwent baseline ECG, detailed ECHO and chemotherapy.

\section{Electrocardiographic assessment}

Standard 12-lead ECGs was recorded in all participants to study the following variables: heart rate, PR interval, QRS complex duration, morphology, OT interval, OT dispersion and ST segment morphology. QT dispersion was calculated as the difference between the longest and the shortest OT distances. Measurements were made by a single experienced cardiologist blinded to study.

\section{Echocardiographic assessment}

Transthoracic ECHO of all patients including 2-D, M-mode, spectral Doppler and TDI measurements were performed. Examinations were carried out by means of Vivid 7 Dimension
(GE Vingmed Ultrasound AS N-3190 Horten, Norway) echocardiography device using $2.5 \mathrm{MHz}$ transducer. Parasternal longaxis left ventricular (LV) end-diastolic and end-systolic diameters and LV ejection fraction were calculated. Mitral early diastolic flow velocity (E), late diastolic flow velocity (A) and E/A ratio were calculated. Tissue Doppler program, in apical 4-chamber imaging analysis was performed via locating the transducer on the intersection point of posterior wall and mitral annulus. Adjusting sampling volume in parallel to wall axis peak early ( $\left.E^{\prime}\right)$ and late ( $A^{\prime}$ ) diastolic flow ratios on lateral mitral annulus were recorded. Entire measurements carried out for each parameter based on 3 calculations and providing their average rates.

\section{Statistical analysis}

Data were analyzed using SPSS (Statistical Package for Social Sciences) version 16.0 (SPSS, Inc., Chicago, Illinois, USA) was used for statistical analysis and expressed as mean \pm standard deviation. The differences in normally distributed parameters were assessed using Student t-test. Paired Samples t-test was used for the evaluation of parameters before and after treatment. The distribution was examined by Shapiro-Wilk test which revealed that for most parameters the $p>0.05$, that is the normal distribution is present. In addition, standard deviation for echocardiographic parameters were in accord with normal distribution. Spearman Correlation test was employed to examine the relations between parameters. In all analysis, a $p$ value $<0.05$ was considered to be statistically significant.

\section{Results}

The study population consisted of 51 patients, one was male. Demographic characteristics of the patients are presented in Table 1. Seven patients died before taking control findings and the two died after study. Obvious heart failure symptoms occurred in two patients and cardiac treatment was started.

Forty-three of the patients $(84.3 \%)$ were given anthracycline group antineoplastic agents (30 patients doxorubicin, 13 patients epirubicin). Patients received anthracycline within the recommended cardiac safe dose limits (doxorubicin average 197 \pm 31 $\mathrm{mg} / \mathrm{m}^{2}$, epirubicin average $484 \pm 160 \mathrm{mg} / \mathrm{m}^{2}$ ). 27 of the patients received anthracycline as dual combination (with cyclophosphamide) and 16 of them received as triplet combination (with cyclophosphamide +5 -fluorouracil). 17 patients were given trastuzumab $(33.3 \%)$. Patients received $4940 \pm 2274 \mathrm{mg}$ trastuzumab. In addition, 21 patients were exposed to radiotherapy, nine to right and twelve to left chest wall. In order to assess homogeneous distribution of the patients included in the study, pre-treatment cardiac findings and demographic data were compared between patients received and did not receive trastuzumab and no significant difference was observed.

\section{Cardiac findings}

In our study, a statistically significant decrease was observed in left ventricular ejection fraction in the sixth month control 
Table 1. Demographic characteristics of the patients

\begin{tabular}{|c|c|c|c|}
\hline Characteristics & & $\begin{array}{c}\text { Quantity, } \\
\text { (n: 51) }\end{array}$ & $\begin{array}{c}\text { Percentage, } \\
\%\end{array}$ \\
\hline Age, years & Mean $\pm S D$ & $51 \pm 12$ & \\
\hline \multirow[t]{2}{*}{ Sex } & Female & 50 & 98.04 \\
\hline & Male & 1 & 1.6 \\
\hline \multirow[t]{2}{*}{ Menopause } & Premenopausal & 31 & 60.8 \\
\hline & Postmenopausal & 19 & 37.3 \\
\hline \multirow{2}{*}{ Diabetes } & Present & 6 & 11.8 \\
\hline & Absent & 45 & 88.2 \\
\hline \multirow[t]{2}{*}{ Hypertension } & Present & 16 & 31.4 \\
\hline & Absent & 35 & 68.4 \\
\hline \multirow{2}{*}{$\begin{array}{l}\text { Estrogen } \\
\text { receptor }\end{array}$} & Positive & 38 & 74.5 \\
\hline & Negative & 13 & 25.5 \\
\hline \multirow{2}{*}{$\begin{array}{l}\text { Progesterone } \\
\text { receptor }\end{array}$} & Positive & 37 & 72.5 \\
\hline & Negative & 14 & 27.5 \\
\hline \multirow{2}{*}{$\begin{array}{l}\text { HER2 } \\
\text { receptor }\end{array}$} & Positive & 18 & 35.3 \\
\hline & Negative & 33 & 64.7 \\
\hline \multirow[t]{6}{*}{ Stage } & Stage I & 5 & 9.8 \\
\hline & Stage IIA & 11 & 21.6 \\
\hline & Stage IIB & 8 & 15.7 \\
\hline & Stage IIIA & 12 & 23.5 \\
\hline & Stage IIIB & 8 & 15.7 \\
\hline & Stage IV & 7 & 13.7 \\
\hline
\end{tabular}

Table 2. Comparison of cardiac findings before and after therapy in all patients

\begin{tabular}{|c|c|c|c|c|}
\hline \multicolumn{2}{|c|}{ Variables } & \multirow{2}{*}{$\begin{array}{l}\begin{array}{c}\text { Before } \\
\text { therapy }\end{array} \\
62.3 \pm 3.3\end{array}$} & \multirow{2}{*}{$\begin{array}{c}\begin{array}{c}\text { After } \\
\text { therapy }\end{array} \\
59.9 \pm 5.9\end{array}$} & \multirow{2}{*}{${ }^{*} \boldsymbol{P}$} \\
\hline \multirow{7}{*}{$\mathrm{ECHO}$} & $\mathrm{EF}(\%)$ & & & \\
\hline & $\mathrm{E}(\mathrm{cm} / \mathrm{sec})$ & $75.8 \pm 17.6$ & $77.5 \pm 20.9$ & 0.55 \\
\hline & $\mathrm{A}(\mathrm{cm} / \mathrm{sec})$ & $77.4 \pm 19.1$ & $86 \pm 18$ & $<0.001$ \\
\hline & $\mathrm{E}^{\prime}(\mathrm{cm} / \mathrm{sec})$ & $12.5 \pm 3.6$ & $10.7 \pm 2.9$ & 0.001 \\
\hline & $\mathrm{A}^{\prime}(\mathrm{cm} / \mathrm{sec})$ & $11.5 \pm 2.4$ & $11.3 \pm 3$ & 0.58 \\
\hline & $E / A$ & $1.01 \pm 0.3$ & $0.9 \pm 0.2$ & 0.03 \\
\hline & $\mathrm{E} / \mathrm{E}^{\prime}$ & $6.6 \pm 2.9$ & $7.7 \pm 3.3$ & 0.04 \\
\hline \multirow{5}{*}{ ECG } & Rate (/min) & $85 \pm 13$ & $88 \pm 13$ & 0.02 \\
\hline & PR (msec) & $143 \pm 16$ & $147 \pm 20$ & 0.09 \\
\hline & QRS (msec) & $81 \pm 11$ & $84 \pm 14$ & 0.17 \\
\hline & QT (msec) & $340 \pm 27$ & $346 \pm 33$ & 0.19 \\
\hline & OTd (msec) & $12 \pm 9$ & $14 \pm 9$ & 0.39 \\
\hline \multicolumn{5}{|c|}{$\begin{array}{l}\text { *Student } \mathrm{t} \text { test, } P<0.05 \text { considered statistically significant. } \\
\text { A - late diastolic flow velocity; A' - late diastolic flow on TDI; E - early diastolic flow } \\
\text { velocity; E'- peak early diastolic flow on TDI; ECG - electrocardiography; } \\
\text { ECHO - echocardiography; EF - ejection fraction }\end{array}$} \\
\hline
\end{tabular}

compared to initial EF $(62.3 \% \pm 3.3$ and $59.9 \% \pm 5.9 ; p=0.002)$. Study also showed the deterioration of diastolic function by chemo- therapy. On Doppler ECHO analysis, a statistically significant increase observed in transmitral A flow velocity $(77.4 \pm 19.1 \mathrm{~cm} /$ sec and $86 \pm 18 \mathrm{~cm} / \mathrm{sec} ; \mathrm{p}<0.001)$ and decrease on E/A ratio $(1.01 \pm 0.3$ and $0.9 \pm 0.2 ; p=0.03)$. Tissue Doppler imaging showed a significant decrease on $E^{\prime}$ value and significant increase on $E / E^{\prime}$ ratio $(12.5 \pm 3.6 \mathrm{~cm} / \mathrm{sec}$ and $10.7 \pm 2.9 \mathrm{~cm} / \mathrm{sec} ; \mathrm{p}=0.001 ; 6.6 \pm 2.9$ and 7.7 $\pm 3.3 ; p=0.04$, respectively). ECG and ECHO findings are presented in Table 2.

We also evaluated study by considering chemotherapy protocols (Table 3); on doxorubicin arm we observed significant differences on $E F(p=0.007), A(p<0.001)$ and $E^{\prime}(p=0.009)$ values and $E / E^{\prime}$ ratio $(p=0.01)$. On epirubicin arm, only $E^{\prime}$ value $(p=0.002)$ was affected on tissue Doppler and there was significant differences on ECG as PR and QT interval prolongation $(p=0.03$ and $\mathrm{p}=0.02$, respectively). In addition, in patients who received anthracycline in triple combination had greater significant reduction on $\mathrm{E}^{\prime}$ value than dual combination on tissue Doppler $(9 \pm 2.4 \mathrm{~cm} / \mathrm{sec}$ and $11.6 \pm 2.6 \mathrm{~cm} / \mathrm{sec} ; \mathrm{p}=0.007)$. There was no correlation between cumulative chemotherapy dose and cardiac findings in patients who received anthracycline. In 16 patients who received trastuzumab, both systolic and diastolic functions were affected; $E F(p=0.04)$ and $E / A(p=0.02)$. There was a significant correlation between total trastuzumab dosage and QRS duration ( $r=0.33$ and $p=0.02$ ). We did not observe any significant difference between patients who received or did not receive trastuzumab on ECHO, Doppler and TDI, but there was significant difference on PR interval on ECG $(141 \pm 20$ versus $156 \pm 18$; $\mathrm{p}=0.01)$. When considering patients who received radiotherapy, there was not any significant differences on EF, ECHO Doppler and TDI except transmitral A value $(76 \pm 19 \mathrm{~cm} / \mathrm{sec}$ and $86 \pm 20 \mathrm{~cm} /$ sec; $p<0.001)$. We also did not observe any changes in results between left or right chest radiation exposures. Control cardiac findings were also compared according to cardiovascular risk factors (hypertension, diabetes and menopause) and there was not any significant change.

\section{Discussion}

In our study, we evaluated early subclinical cardiotoxicity of the chemotherapy that is under the upper limit of the recommended cardiac safety dose in patients with breast cancer. The study showed chemotherapy affects subclinically left ventricular systolic and diastolic functions. That affect is pronounced in patients who received multiple chemotherapy combinations. In addition, diastolic parameters present early signs of LV dysfunction in patients receiving chemotherapy and TDI appeared more sensitive than conventional echo Doppler in order to show diastolic dysfunction.

Anthracyclines are well-known antineoplastic agents about cardiotoxicity in patients with breast cancer. Doxorubicin and epirubicin are commonly used and effective and known dose dependent cardiac damage (8). Doxorubicin has lower risk of congestive heart failure under dose of $450 \mathrm{mg} / \mathrm{m}^{2}(0.1 \%)$, but moderate of $550 \mathrm{mg} / \mathrm{m}^{2}(7 \%)$ and high risk at upper than $1000 \mathrm{mg} /$ $\mathrm{m}^{2}(50 \%)(9,10)$. Epirubicin is known cardiac safety up to dose of 
Alıci et al.

Table 3. Comparison of cardiac findings before and after therapy by each treatment group

\begin{tabular}{|c|c|c|c|c|c|c|c|c|c|c|}
\hline & & \multicolumn{3}{|c|}{ Doxorubicin (n:30) } & \multicolumn{3}{|c|}{ Epirubicin (n:13) } & \multicolumn{3}{|c|}{ Trastuzumab (n:16) } \\
\hline \multicolumn{2}{|c|}{ Variables } & $\begin{array}{l}\text { Before } \\
\text { therapy }\end{array}$ & $\begin{array}{c}\text { After } \\
\text { therapy }\end{array}$ & ${ }^{*} \boldsymbol{P}$ & $\begin{array}{l}\text { Before } \\
\text { therapy }\end{array}$ & $\begin{array}{c}\text { After } \\
\text { therapy }\end{array}$ & ${ }^{*} \boldsymbol{P}$ & $\begin{array}{l}\text { Before } \\
\text { therapy }\end{array}$ & $\begin{array}{c}\text { After } \\
\text { therapy }\end{array}$ & ${ }^{*} \boldsymbol{P}$ \\
\hline \multirow{7}{*}{$\mathrm{ECHO}$} & $\mathrm{EF}(\%)$ & $62.1 \pm 3.2$ & $60 \pm 5.3$ & 0.007 & $61.6 \pm 4.1$ & $59.9 \pm 5.2$ & 0.14 & $62.7 \pm 2.5$ & $59 \pm 5.8$ & 0.04 \\
\hline & $\mathrm{E}(\mathrm{cm} / \mathrm{sec})$ & $77 \pm 18$ & $79 \pm 19$ & 0.51 & $71 \pm 16$ & $74 \pm 30$ & 0.73 & $75 \pm 16$ & $72 \pm 19$ & 0.36 \\
\hline & $\mathrm{A}(\mathrm{cm} / \mathrm{sec})$ & $78 \pm 19$ & $86 \pm 16$ & $<0.001$ & $78 \pm 15$ & $85 \pm 22$ & 0.25 & $79 \pm 21$ & $85 \pm 20$ & 0.1 \\
\hline & $\mathrm{E}^{\prime}(\mathrm{cm} / \mathrm{sec})$ & $13.2 \pm 3.6$ & $11.4 \pm 2.8$ & 0.009 & $12 \pm 2.8$ & $9 \pm 1.9$ & 0.002 & $11 \pm 3.5$ & $10.9 \pm 2.7$ & 0.85 \\
\hline & $A^{\prime}(\mathrm{cm} / \mathrm{sec})$ & $11.5 \pm 2.2$ & $11.2 \pm 2.7$ & 0.49 & $12.3 \pm 3$ & $11.9 \pm 3$ & 0.59 & $11.8 \pm 2.4$ & $11.3 \pm 3.6$ & 0.55 \\
\hline & $E / A$ & $1.03 \pm 0.3$ & $0.93 \pm 0.2$ & 0.19 & $0.94 \pm 0.3$ & $0.87 \pm 0.3$ & 0.65 & $0.98 \pm 0.2$ & $0.86 \pm 0.2$ & 0.02 \\
\hline & $E / E^{\prime}$ & $6.3 \pm 2.3$ & $7.3 \pm 2.7$ & 0.01 & $6 \pm 1.6$ & $8.7 \pm 4.2$ & 0.1 & $7.7 \pm 4$ & $7.1 \pm 3.2$ & 0.53 \\
\hline \multirow{5}{*}{ ECG } & Rate (/min) & $85 \pm 11$ & $88 \pm 13$ & 0.14 & $91 \pm 18$ & $93 \pm 15$ & 0.55 & $81 \pm 10$ & $85 \pm 11$ & 0.2 \\
\hline & PR (msec) & $142 \pm 16$ & $145 \pm 21$ & 0.39 & $141 \pm 20$ & $149 \pm 20$ & 0.03 & $149 \pm 13$ & $156 \pm 18$ & 0.11 \\
\hline & QRS (msec) & $82 \pm 12$ & $84 \pm 13$ & 0.21 & $80 \pm 6$ & $86 \pm 17$ & 0.37 & $83 \pm 11$ & $85 \pm 11$ & 0.16 \\
\hline & $\mathrm{QT}$ (msec) & $344 \pm 29$ & $341 \pm 28$ & 0.6 & $335 \pm 22$ & $358 \pm 39$ & 0.02 & $348 \pm 32$ & $352 \pm 30$ & 0.56 \\
\hline & QTd (msec) & $13.4 \pm 8$ & $13.4 \pm 10$ & 1 & $13 \pm 14$ & $16 \pm 10$ & 0.63 & $14 \pm 10$ & $16 \pm 7$ & 0.3 \\
\hline
\end{tabular}

$950-1000 \mathrm{mg} / \mathrm{m}^{2}(9,10)$. Anthracycline cardiotoxicity courses long-term silent and progressive so patients' cardiac monitoring becomes very important (11). Today, conventional ECHO and Doppler ECHO are the most widely used method for monitoring chemotherapy-induced cardiotoxicity. Left ventricular endocardial fractional shortening and ejection fraction are often used for evaluating LV dysfunction in oncology patients (12). In our study, a significant decrease in EF was experienced, despite anthracyclines were given at a dose under the specified safe amounts $(62.3 \% \pm 3.3$ and $59.9 \% \pm 5.9 ; p=0.002)$. Especially reduction is more obvious with combination therapies. Earlier studies showed that diastolic dysfunction occurs earlier than systolic dysfunction in these patients and cardiac involvement may be overlooked because of symptoms appear late (13). In our study, we observed significant impairment on diastolic parameters.

Epirubicin is demonstrated less cardiotoxic anthracycline than doxorubicin in many studies $(14,15)$. In our study, a small group of patients $(n=13)$ received epirubicin. Results showed us, as is known; cardiac impairment was lower than doxorubicin received patients. Although doxorubicin treated patients had significant changes on conventional echo and Doppler ECHO, epirubicin treated ones did not, but on TDI $E^{\prime}$ value was decreased.

It is shown that pulsed tissue Doppler imaging taken from various regions of LV (mitral annulus, basal LV lateral and basal LV posterior wall) provides more underlined information in demonstrating early (1-3 months) and late ( $3.5 \pm 0.6$ years) LV myocardial function changes after doxorubicin therapy (16-18). In our study, we observed significant decrease on $E^{\prime}$ value on TDI and increase on $E / E^{\prime}$ ratio. In patient who received epirubicin, despite no significant changes on conventional echo and Doppler echo, there was significant decrease on $\mathrm{E}^{\prime}$ value. These findings show us TDI is more sensitive than conventional Doppler echo to evaluate diastolic functions.

Trastuzumab is also a well-known cardiotoxic agent used in breast cancer. Unlike anthracyclines that affect is considered reversible. It has been observed that trastuzumab caused LVEF decrease in $7.5 \%$ and congestive heart failure in $1.9 \%$ of in a meta-analysis of 10 randomized controlled trials published on the cardiotoxicity of trastuzumab (19). The same study showed that the cardiotoxicity goes up in combination therapy with anthracyclines and cardiotoxicity is also emphasized that similar rate of cardiotoxicity was observed in the early stage or metastatic breast cancer. In our study, there was significant decrease on LVEF on E/A ratio in patients who received trastuzumab at the sixth month of treatment.

ECG may give some information about chemotherapy-induced cardiotoxicity. On anthracycline cardiotoxicity, generally nonspecific ST segment and T wave changes, increase in QRS voltage and elongation of $\mathrm{OT}$ interval are observed (20). In our study, we observed heart rate increase and PR interval prolongation but not statistically significant. Nevertheless, there were differences between the chemotherapy regimens such as epirubicin. Significant PR and $\mathrm{OT}$ interval prolongations were observed in patients who received epirubicin. These findings show that despite absence of cardiotoxicity signs of ECG, systolic and diastolic dysfunction were observed in our study.

Conventional ECHO and TDI are appeared comparatively easy, accessible and cheap to follow-up cardiac functions in patients exposed to cytotoxic drugs. However, recent studies showed that speckle tracking, two-dimensional-strain imaging (21) and three-dimensional ECHO (22) are more sensitive and less temporal and observer variability in early detection of chemotherapy related cardiac damage. Several methods can be 
used to show cardiotoxicity beyond ECHO such as multigated radionuclide angiography, cardiac magnetic resonance imaging, and cardiospecific biomarkers (23). All these methods may give more cardiac information but are used at the expense of cost, radiation and speciality.

\section{Study limitations}

Small sample size was a limitation of our study. It would be better to strengthen the study with cardiac biomarkers such as troponin and NT-proBNP values.

\section{Conclusion}

Despite using under well-known cardiac safety dosages, anthracyclines can damage the heart subclinically. Trastuzumab may increase that impairment. Tissue Doppler Imaging may be more sensitive than ECG, conventional ECHO and Doppler for determining the subclinical cardiac damage. We recommend that close follow up of these patients by non-invasive tool by echocardiography is essential.

\section{Conflict of interest: None declared.}

Peer-review: Externally peer-reviewed.

Authorship contributions: Concept - H.A.; Design - S.E.; Supervision - V.D.; Resource - M.Ç.; Materials - O.B.; Data collection \&/or processing - H.A.; Analysis \&/or interpretation - H.A.; Literature search - 0.B.; Writing - H.A.; Critical review - V.D.; Other - F.Y.

\section{References}

1. Hong RA, limura T, Sumida KN, Eager RM. Cardio-oncology/oncocardiology. Clin Cardiol 2010; 33: 733-7. [CrossRef]

2. Jemal A, Bray F, Center MM, Ferlay J, Ward E, Forman D. Global cancer statistics. CA Cancer J Clin 2011; 61: 69-90. [CrossRef]

3. DeSantis C, Siegel R, Bandi P, Jemal A. Breast cancer statistics, 2011. CA Cancer J Clin 2011; 61: 409-18. [CrossRef]

4. Hossain A, Chen A, Ivy P, Lenihan DJ, Klatman J, Taddei-Peters W, et al. The importance of clinical grading of heart failure and other cardiac toxicities during chemotherapy: updating the common terminology criteria for clinical trial reporting. Heart Fail Clin 2011; 7: 373-84. [CrossRef]

5. Gillespie HS, McGann CJ, Wilson BD. Noninvasive diagnosis of chemotherapy related cardiotoxicity. Curr Cardiol Rev 2011; 7: 234-44. [CrossRef]

6. Ganz WI, Sridhar KS, Ganz SS, Gonzalez R, Chakko S, Serafini A. Review of tests for monitoring doxorubicin-induced cardiomyopathy. Oncology 1996; 53: 461-70. [CrossRef]
7. Mann DL, Krone RJ. Cardiac disease in cancer patients: an overview. Prog Cardiovasc Dis 2010; 53: 80-7. [CrossRef]

8. Shan K, Lincoff AM, Young JB. Anthracycline-induced cardiotoxicity. Ann Intern Med 1996; 125: 47-58. [CrossRef]

9. Allen A. The cardiotoxicity of chemotherapetic drugs. Semin Oncol 1992; 19: 529-42.

10. Tolba KA, Deliargyris EN. Cardiotoxicity of cancer therapy. Cancer Invest 1999; 17; 408-22. [CrossRef]

11. Wu AH. Cardiotoxic drugs: clinical monitoring and decision making Heart 2008; 94: 1503-9. [CrossRef]

12. Zile MR, Baicu CF, GaaschWH. Diastolic heartfailure--abnormalities in active relaxation and passive stiffness of the left ventricle. $\mathrm{N}$ Engl J Med 2004; 350: 1953-9. [CrossRef]

13. Tassan-Mangina S, Codorean D, Metivier M, Costa B, Himberlin C, Jouannaud $\mathrm{C}$, et al. Tissue Doppler imaging and conventional echocardiography after anthracyclines treatment in adults: early and late alterations of left ventricular function during a prospective study. Eur J Echocardiogr 2006; 7: 141-6. [CrossRef]

14. Fumoleau $P$, Roché $H$, Kerbrat $P$, Bonneterre $J$, Romestaing $P$, Fargeot $P$, et al; French adjuvant study group. Long-term cardiac toxicity after adjuvant epirubicin-based chemotherapy in early breast cancer: French Adjuvant Study Group results. Ann Oncol 2006; 17: 85-92. [CrossRef]

15. Baldini E, Prochilo T, Salvadori B, Bolognesi A, Aldrighetti D, Venturini $M$, et al. Multicenter randomized phase III trial of epirubicin plus paclitaxel vs epirubicin followed by paclitaxel in metastatic breast cancer patients: focus on cardiac safety. $\mathrm{Br} \mathrm{J}$ Cancer 2004; 91: 45-9. [CrossRef]

16. Lenihan DJ, Esteva FJ. Multidisciplinary strategy for managing cardiovascular risks when treating patients with early breast cancer. Oncologist 2008; 13: 1224-34. [CrossRef]

17. Galderisi M, Nistri S, Ansalone G, Di Salvo G, Dini FL, Gallina S, et al. Pulsed tissue Doppler illustrated to a resident in cardiology. $G$ Ital Cardiol 2007; 8: 92-101.

18. Jassal DS, Han SY, Hans C, Sharma A, Fang T, Ahmadie R, et al. Utility of tissue Doppler and strain rate imaging in the early detection of trastuzumab and anthracycline mediated cardiomyopathy. J Am Society Echocardiogr 2009; 22: 418-24. [CrossRef]

19. Chen T, Xu T, Li Y, Liang C, Chen J, Lu Y, et al. Risk of cardiac dysfunction with trastuzumab in breast cancer patients: a metaanalysis. Cancer Treat Rev 2011; 37: 312-20. [CrossRef]

20. Ohnishi K, Yoshida H, Shigeno K, Nakamura S, Fujisawa S, Naito K, et al. Prolongation of the QT interval and ventricular tachycardia in patients treated with arsenic trioxide for acute promyelocytic leukemia. Ann Intern Med 2000; 133: 881-5. [CrossRef]

21. Mornoş C, Petrescu L. Early detection of anthracycline-mediated cardiotoxicity: the value of considering both global longitudinal left ventricular strain and twist. Can J Physiol Pharmacol 2013; 91: 601-7. [CrossRef]

22. Mor-Avi V, Lang RM. Is echocardiography reliable for monitoring the adverse cardiac effects of chemotherapy? J Am Coll Cardiol 2013; 61: 85-7. [CrossRef]

23. Oreto L, Todaro MC, Umland MM, Kramer C, Oamar R, Carerj S, et al. Use of echocardiography to evaluate the cardiac effects of therapies used in cancer treatment: what do we know? J Am Soc Echocardiogr 2012; 25: 1141-52. [CrossRef] 